

Research Article

\title{
Application of Posicast controller with SVC in wind-diesel hybrid power system model
}

\author{
Pabitra Kumar Guchhait ${ }^{1}$. Abhik Banerjee ${ }^{1}$ (I) $\cdot$ V. Mukherjee $^{2}$
}

Received: 20 January 2020 / Accepted: 27 February 2021 / Published online: 16 March 2021

(C) The Author(s) 2021 OPEN

\begin{abstract}
Posicast controller is used to damp out oscillations of power system by changing excitation of the reference signal. The main purpose of this controller is to reduce the overshoot and the rising time of the transient voltage response of power system. In the present work, Posicast controller and static VAR controller (SVC) have been used to enhance the stability under any form of small disturbance of a wind-diesel hybrid power system (WDHPS) model. Stability of the hybrid model is, mainly, affected by the active and the reactive power unbalance. In this paper, reactive power unbalance has been carried out and it may be handled by using these two controllers. In the studied WDHPS model, a power system stabilizer (mainly, PSS3B) is also included along with the Posicast with SVC controller and performance of the hybrid model is investigated with the help of different soft computing techniques. Soft computing techniques are, basically, used to adjust the different parameters of the studied WDHPS based model for smooth and healthy operations of the hybrid model. The employed technique establishes better performance of the studied WDHPS based model in terms of superior dynamic reactive power compensation offered in real-time.
\end{abstract}

Index Terms Posicast controller - Wind-diesel hybrid power system model · Static VAR compensator · Power system stabilizer · Transient stability

\section{Introduction}

In the twenty-first century, due to continuous increase in population and industry, power demand increases day by day and the demand is not fulfilled only by conventional energy sources. Therefore, alternative sources of energy are required. Non-conventional or renewable sources are the best option to fulfill the deficit of power and it has also an advantage that it is eco-friendly in nature. But due to various types of environmental issues and allied uncertainties, only renewable energy sources (RESs) do not fulfill the power demands of the consumers throughout the day. Reliability of power generation as well as consumption in the consumer premises is also ambiguous in nature. To overcome the situation and to provide continuous power to the consumers, the engineers and the scientists have successfully developed a new strategy which has laid down more than one kind of energy sources and is operated in synchronism to fulfill the continuous load demand in the consumer premises. These types of energy system models, consisting of more than one energy sources, are commonly known as hybrid power system (HPS) model $[1,2]$.

In the present work, a hybrid model consists of a conventional energy source (like diesel engine) and a nonconventional energy source (such as wind engine) have been considered. The hybrid model is not only necessary to be a wind-diesel combination $[3,4]$ but it also may be

Abhik Banerjee, abhik@nitap.ac.in; Pabitra Kumar Guchhait, pabitra.phd@nitap.ac.in; V. Mukherjee, vivek_agamani@yahoo.com $\left.\right|^{1}$ Department of Electrical Engineering, National Institute of Technology, Yupia, Arunachal Pradesh, India. ${ }^{2}$ Department of Electrical Engineering, Indian Institute of Technology (Indian School of Mines), Dhanbad, Jharkhand, India. 
combination of (a) wind-diesel and hydro [5], (b) winddiesel and fuel cell [6], (c) wind-diesel and photovoltaic (PV) [7] or many others. This kind of HPS model has many advantages such as almost pollution free operation, minimum cost of fuel for energy production, environment friendly and, mostly, power for all the day. But the main disadvantage associated with this is the reactive power unbalance which takes place in the system under any kind of load demand variation and intermittent nature of RESs [8]. Reactive power unbalance in the HPS causes problems, like stability issues, power losses and severe kinds of faults [9]. Therefore, to recover HPS from this kind of troubles, reactive power requirement is to be compensated. Many processes have been described in the literature to compensate the reactive power of this HPS. Reactive power to the HPS may be provided by a switched capacitor but it regulates the terminal voltage profile in discrete manner [10]. But implementation of power electronics equipment based flexible AC transmission systems (FACTS) improves the reactive power unbalance very significantly. Different kinds of FACTS devices like static VAR compensator (SVC) [11, 12], static synchronous compensator [13], unified power flow controller [14] etc. are employed to compensate reactive power of the HPS. However, SVC may be one of the effective FACTS devices for managing the reactive power of HPS and improving stability of the model [15].

Different varieties of SVC controllers have been presented by many authors such as proportional controllers $[16,17]$, proportional-integral controllers [18, 19], proportional-integral-derivative controllers $[20,21]$ and lead-lag controllers $[22,23]$. Controller parameters of SVC depend upon different load conditions. Different controller parameters are required to be tuned by the use of various intelligent soft computing methods. It has been observed that genetic algorithm (GA) [23, 24], artificial neural network $[24,25]$, seeker optimization algorithm (SOA) [26], gravitational search algorithm (GSA) [27], opposition-based GSA [27] techniques are used to optimize several controlling parameters of different HPS model. A Takagi Sugeno fuzzy logic controller has been used to tune the controller parameters in real time conditions [9]. In this paper, a metaheuristic algorithm (named as symbiosis organism search (SOS) [28] algorithm) has been considered to adjust the parameters of the studied Posicast and SVC controller based wind-diesel HPS (WDHPS) model and the superiority of the adopted algorithm has been verified while comparing the performance with other algorithms (like binary coded GA (BGA) and SOA).

Posicast controller has been applied successfully in this hybrid model due to its excellent features of controlling terminal voltage of the exciter [29]. Therefore, it may be preferred one to improve the transient voltage and also the small signal stability [30]. In power system, Posicast controller, mainly, damps out the low frequency oscillations within the range of $0.2-3 \mathrm{~Hz}[31,32]$. Posicast controller has been considered with the STATCOM for voltage control for fixed speed induction generator wind farm (see [33]). This controller has been also successfully applied in the multi-machine power system to minimize the power system oscillations (refer [34]). The Posicast control method has been also used in static shunt compensators for better controlling purposes of the system (as appeared in [35]). Power system stabilizer (PSS) is also considered for the adopted test cases. PSSs are broadly used in power system to control the inter area mode of oscillations. Sometimes, PSS does not perform its task due to its instability under negative damping situation $[36,37]$. Now, to overcome the small oscillation problems of the synchronous generator (SG) based diesel engine model, a Posicast controller with PSS3B (a dual input type PSS) is used in the present work.

The concept of Posicast controller has been used in papers related to the effect of AVR model, in renewable energy applications (as in [36-40]) and also the impact of SVC controller has been discussed in the literatures for reactive power compensation. However, their combined impact on a hybrid power system model is yet to be surfaced in the recent state-of-the-art literature. This motivates the present authors to deal with the combined impact of SVC controller, Posicast controller and PSS for a HPS for renewable energy based application.

With reference of the above, the principle contributions of the present research work are mentioned below:

(a) The Posicast controller is investigated to mitigate the oscillations of the considered WDHPS which, in turn, improves the system transient performance.

(b) The algorithms like BGA, SOA and SOS are deployed to tune the parameters of different adopted controllers related to the studied WDHPS.

(c) The results obtained, while employing SVC, Posicast and PSS3B in the studied WDHPS, are compared with other types of considered configurations where Posicast controller is not present.

(d) The efficacy of SOS algorithm over the other applied algorithms like BGA and SOA for the adopted model configurations is established.

\section{Mathematical modeling Of WDHPS}

In the studied WDHPS model (see Fig. 1), it has been observed that, for the operation of induction generator (IG) based wind turbine, reactive power is required. Additionally, as the load is reactive in nature, it will also draw reactive power. So, the requirement of reactive power can be fulfilled 


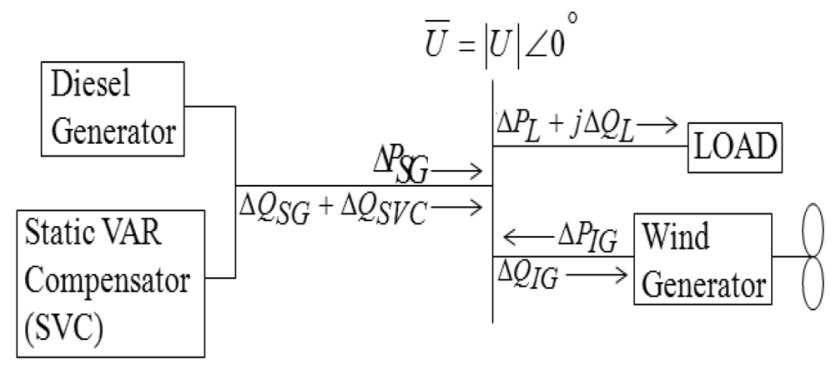

Fig. 1 A schematic diagram of the studied WDHPS model

by the SG based diesel engine and SVC and the reactive power balance equation with respect to Fig. 1 is given in (1)

$\Delta Q_{S G}+\Delta Q_{S V C}=\Delta Q_{I G}+\Delta Q_{L}$

where, the terms $\Delta Q_{S G}, \Delta Q_{S V C}$ are, respectively, the amount of reactive power supplied by the SG and the SVC while $\Delta Q_{I G}, \Delta Q_{L}$ are, in sequence, the amount reactive power absorbed by the IG and the load.

If any disturbance occurs in the studied model, the reactive power $\left(\Delta Q_{L}\right)$ requirement is also varying. The system voltage may be affected due to the change in load voltage which, subsequently, changes the reactive power demand by the load as well as other components of the system. Mismatch of reactive power may be fulfilled by proper compensation (i.e. $\Delta Q_{S G}+\Delta Q_{S V C}-\Delta Q_{I G}-\Delta Q_{L}$ ) and changes the system voltage in two different ways [4]. Firstly, it increases the electromagnetic energy absorption of IG $\left(\Delta E_{M}\right)$ at the rate of $\frac{d}{d t}\left(E_{M}\right)$ and secondly, it also increases the reactive load consumption and, for that, the voltage change will be governed by (2) (refer Fig. 2a for constant speed/slip of IG and for Fig. $2 b$ for variable speed/slip of IG).

$\Delta U(s)=\left(\frac{K_{u}}{1+s T_{u}}\right)\left(\Delta Q_{S G}+\Delta Q_{S V C}-\Delta Q_{I G}-\Delta Q_{L}\right)$

In (2), the terms, $K_{u}$ and $T_{u}$ are, respectively, the energy balance loop constant and the time constant [4].

\subsection{Modelling of SG, IG, SVC and PSS blocks}

Reactive power demand and supply by the various power system components like SG, IG and SVC are described below.

Reactive power supplied by the SG $\left(\Delta Q_{S G}\right)$ for an incremental load voltage change $(\Delta U)$ is given by (3) (refer Fig. 2a).

$\Delta Q_{S G}(s)=K_{1} \Delta E_{q}(s)+K_{2} \Delta U(s)$

In (3), $\Delta E_{q}$ (the incremental change in internal armature emf under steady state) is proportional to the direct axis field flux and, for the small perturbation, $\Delta E_{q}(s)$ may be obtained by (4).

$\Delta E_{q}(s)=\left(\frac{1}{1+s T_{g}}\right)\left(K_{3} \Delta E_{f d}(s)+K_{4} \Delta U(s)\right)$

Similarly, the demand in reactive power (i.e., $\Delta Q_{I G}$ ) by the IG for its running under constant slip (s) may be written in terms of generator voltage $(\Delta U(s)$ ) as in (5) (refer Fig. 2a).

$\Delta Q_{I G}(s)=K_{5} \Delta U(s)$

The reactive power demand of wind turbine based IG also varies with the wind speed and, under varying speed or slip (s), the reactive power demand may be expressed as in (6) (refer Fig. 2b).

$\Delta Q_{I G}(s)=K_{6} \Delta P_{I W}(s)+K_{7} \Delta U(s)$

The various constant terms associated with (3)-(6) are discussed in Appendix Section (see Section A1).

In the studied WDHPS model, the diesel engine based SG gives reactive power to the system but the inductive load and the IG draw reactive power from the system for their operation. So, from (1), it may be apprehended that there is reactive power mismatch in the system for any kind of small disturbance leading to a serious problem after certain limitations (refer [27]). This mismatch of reactive power is fulfilled by an SVC block [41, 42]. The mathematical modelling of SVC block (refer Fig. 2a, b), in s-domain, may be written as in (7) and(8) (refer [36]).

$\Delta B_{s 1}(s)=\left(\frac{K_{s}}{1+s T_{s}}\right)\left(\Delta U_{r e f}^{*}-\Delta U\right)$

$\Delta B_{s 2}(s)=\left(\frac{1+s T_{s 1}}{1+s T_{s 2}}\right) \Delta B_{s 1}(s)$

The various tuneable parameters of the considered FACTS (i.e., SVC) controller are $K_{s}, T_{s}, T_{s 1}$ and $T_{s 2}$. The maximum and the minimum ranges of this considered SVC parameters are given in Table 1 [27].

In the studied model, a dual input PSS (namely, PSS3B) model is used rather than the other types of PSS models due to its various advantages for small inter area oscillation control (see [26]). In the PSS3B controller (see Fig. 3a), there are two inputs (i.e., $\Delta \omega_{r}$ and $\Delta T_{e}$ ). The various PSS3B controller parameters (i.e., $K_{s 1}, K_{s 2}, T_{d 1}, T_{d 2}, T_{d 3}$ and $T_{d 4}$ ) are to be tuned while employing different soft computing based techniques for smooth and healthy control of the studied model [43]. The ranges of PSS3B parameters are also placed in Table 1 [26]. 
Fig. 2 Transfer function model of the studied WDHPS for a constant speed and $\mathbf{b}$ variable speed (a)

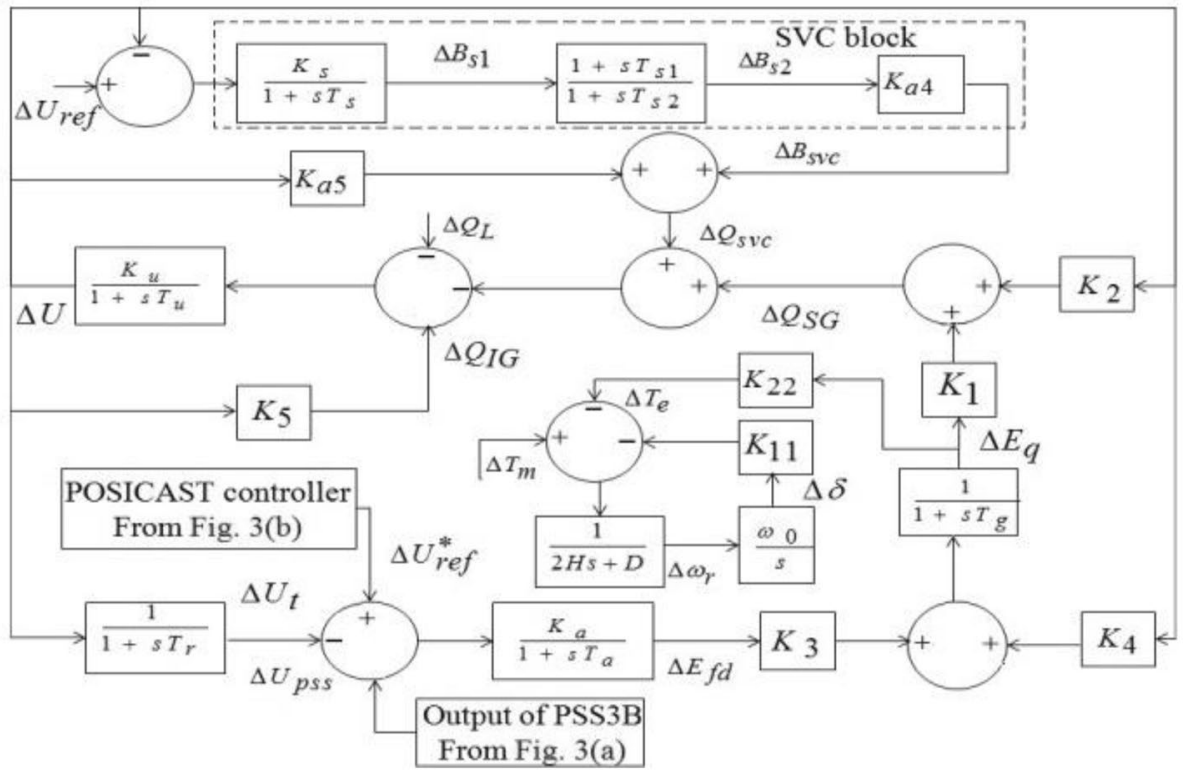

(b)

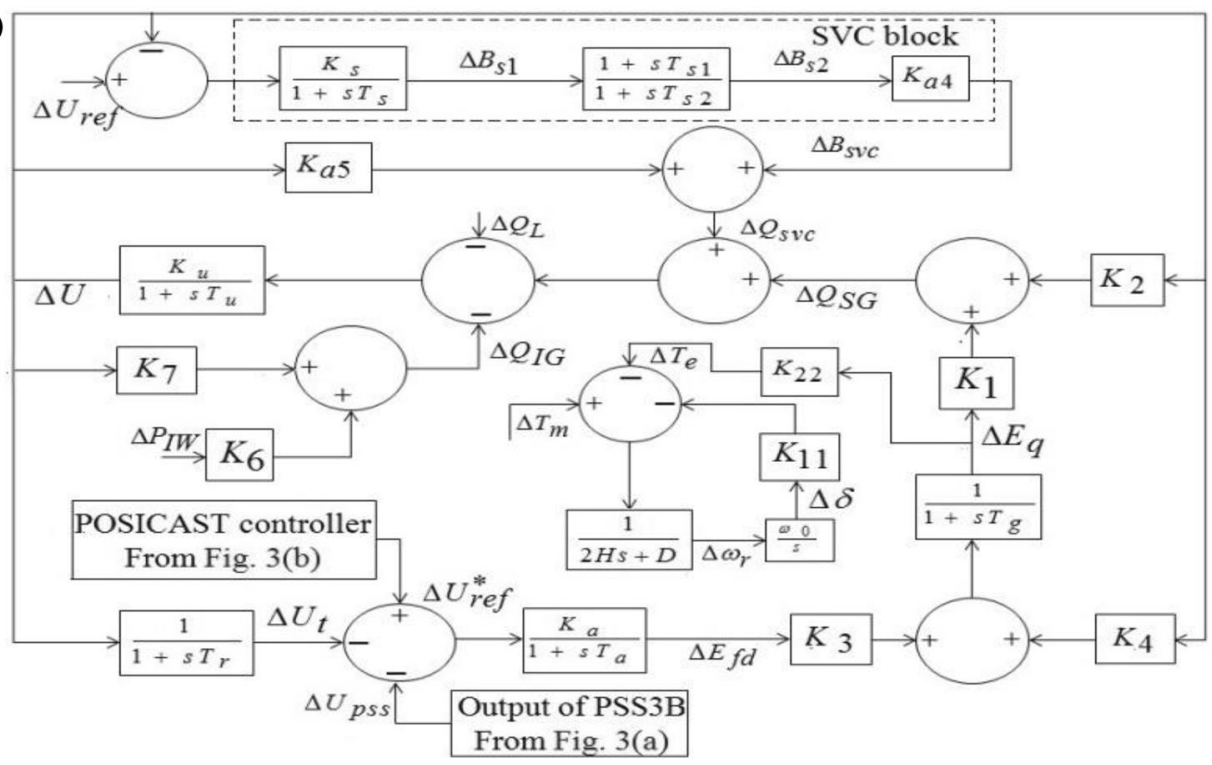

Table 1 Parameter ranges of different controllers

\begin{tabular}{llll}
\hline Controller & Parameters & Minimum limit & Maximum limit \\
\hline SVC & $K_{s}$ & 10 & 100 \\
& $T_{s}, \mathrm{~s}$ & 0.005 & 0.05 \\
& $T_{s 1}, \mathrm{~s}$ & 0.005 & 0.05 \\
& $T_{s 2}, \mathrm{~s}$ & 0.005 & 0.05 \\
PSS & $K_{s 1}$ & -10 & 100 \\
& $K_{s 2}$ & 10 & 100 \\
& $T_{d 1}, \mathrm{~s}$ & 0.001 & 0.005 \\
& $T_{d 2}, \mathrm{~s}$ & 0.001 & 0.005 \\
& $T_{d 3}, \mathrm{~s}$ & 0.001 & 0.005 \\
& $T_{d 4}, \mathrm{~s}$ & 0.001 & 0.005 \\
Posicast & $K_{p}$ & 1 & 10 \\
& $T_{d}, \mathrm{~s}$ & 0.5 & 1.0 \\
\hline
\end{tabular}

\subsection{Modelling of Posicast controller}

The Posicast controller was first invented in 1957 by Smith in [31] to mitigate the oscillation of a lightly damped system. Posicast means positive cast. For a step input response, Posicast controller reforms the input into two steps. In the first step, Posicast controller is scaled in which first peak of the oscillatory response meets precisely to the desired final value. In the second step, the input is scaled with time-delayed precisely and cancels the remaining oscillatory response, thus, causing the system output response at its desired value. Modeling of Posicast controller for the studied WDHPS model is presented in Fig. 3b. The open loop transfer function model of the step input Posicast controller [30] is defined as in (9). 
(a)

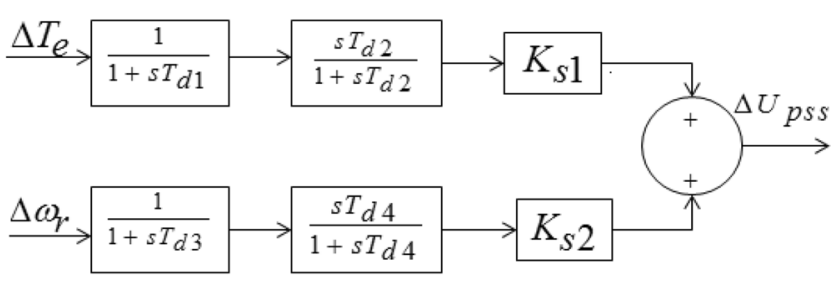

(b)

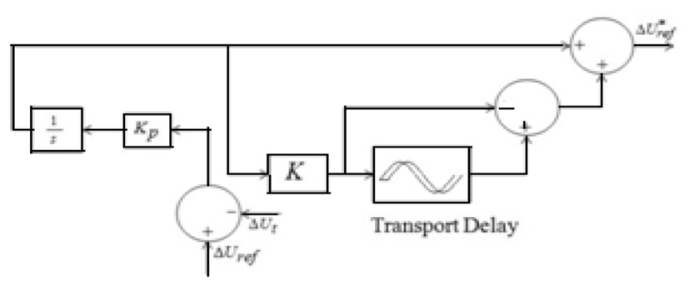

Fig. 3 Controller model of $\mathbf{a}$ PSS3B and $\mathbf{b}$ Posicast controller

$P(s)=\left(K_{p}+\frac{1}{s}\right) K\left[-1+e^{-s T_{d}}\right]$

The different controller parameters (i.e., $K_{p}$ and $T_{d}$ ) of the Posicast controller, as given in Fig. 3(b), are to be tuned properly for optimum control of the system. The tuning ranges of these parameters are also given in Table 1.

\subsection{State-space model of studied WDHPS}

The state-space realisation for the studied model has been presented in (10).

$\frac{d X}{d t}=A X+B U+C P$

In (10), $\boldsymbol{X}, \boldsymbol{U}$ and $\boldsymbol{P}$ are, in order, the state, the control and the disturbance vectors and $A, B$ and $C$ are, in sequence, their respective matrices.

The studied WDHPS model has been tested for two different cases, firstly equipped with SVC and Posicast controller (named as, Model + SVC + Posicast) and secondly, employing SVC, Posicast and PSS3B controller (named as, Model + SVC + Posicast + PSS3B). For these two considered conditions, the different state vectors of the studied WDHPS model are given below:

Case 1 Model + SVC + Posicast

The elements of state-space form of this configuration are as in (11)-(14).

$X=\left[\Delta \omega_{r} \Delta \delta \Delta E_{f d} \Delta U_{t} \Delta E_{q} \Delta U \Delta U_{r e f}^{*} \Delta B_{s 1} \Delta B_{s 2}\right]^{T}$

$U=\left[\begin{array}{ll}\Delta U_{\text {ref }} & \Delta T_{m}\end{array}\right]^{T}$

$P_{1}=\left[\Delta Q_{\text {ref }}\right]$ for constant slip/speed model

$P_{2}=\left[\Delta Q_{\text {ref }} \Delta P_{I W}\right]^{T}$ for variable slip/speed model
The parameters to be tuned for this case are $K_{s}, T_{s}, T_{s 1}$ and $T_{s 2}$ for SVC controller while $K_{p}$ and $T_{d}$ are for Posicast controller.

Case 2 Model + SVC + Posicast + PSS3B

Equations (15)-(18) represent the elements of state-space representation of configuration 2.

$X=\left[\Delta X_{1} \Delta X_{2} \Delta X_{3} \Delta X_{3} \Delta \omega_{r} \Delta \delta \Delta E_{f d} \Delta U_{t} \Delta E_{q} \Delta U \Delta U_{\text {ref }}^{*} \Delta B_{s 1} \Delta B_{s 2}\right]^{T}$ (15)

$U=\left[\begin{array}{ll}\Delta U_{r e f} & \Delta T_{m}\end{array}\right]^{T}$

$P_{1}=\left[\Delta Q_{\text {ref }}\right]$ for constant slip/speed model

$P_{2}=\left[\Delta Q_{r e f} \Delta P_{I W}\right]^{T}$ for variable slip/speed model

Similarly, for this test case, the tuneable parameters are $K_{s}, T_{s}, T_{s 1}$ and $T_{s 2}$ for SVC; $K_{p}$ and $T_{d}$ are for Posicast controller while $K_{s 1} K_{s 21} T_{d 1}, T_{d 2}, T_{d 3}$ and $T_{d 4}$ are for PSS3B controller.

\section{Mathematical problem formulation}

Reactive power compensation of the studied model may be checked in terms of various optimal mathematical parameters. Various mathematical terms, as employed for the present work, are defined in the subsequent sections.

\subsection{Measurement of various performance indices}

The various performance indices are defined in (19)-(21) [44]. Integral absolute error $(I A E)=\int_{0}^{\infty}\left|U_{t}(t)\right| d t$

Integral time square error $(I T S E)=\int_{0}^{\infty} t U_{t}^{2}(t) d t$

Integral square error $(I S E)=\int_{0}^{\infty} U_{t}^{2}(t) d t$ 


\subsection{Performance based on figure of demerit (FOD)}

To enhance relative stability of the model and to pull off better damping of electro-mechanical modes of oscillation, the objective function (named as FOD) may be minimized. Minimization of FOD ensures minimum incremental change in terminal voltage. This may be achieved by optimizing the power system transient parameters (like, steady state error $\left(E_{S S}\right)$, settling time $\left(t_{s}\right)$, rising time $\left(t_{r}\right)$ and maximum overshoot $\left(M_{p}\right)$ ) of the obtained terminal voltage profile. In terms of above control parameters, a performance index (namely, FOD) [44] is defined in (22).

$F O D=\left(M_{P}+E_{S S}\right) *\left(1-e^{-\gamma}\right)+\left(t_{s}-t_{r}\right) * e^{-\gamma}$

In the present work, the value set up for $\gamma$, in line with [44], is 1.0 .

\subsection{Eigenvalue or fitness function based analysis}

Parameters related to the isolated WDHPS model are to be optimized in such a manner that the system relative stability may be enhanced and damping of electromechanical oscillation is achieved $[45,46]$. A fitness function $(J)$ is chosen which is inter-related with the optimizing parameters. By minimizing this fitness function $(J)$, the closed loop poles (i.e., eigenvalues of the system) are made more shifted towards left side of the $j w$-axis. More negative eigenvalues mean that the system relative stability as well as damping ratio may be enhanced. This fitness function may be defined as in (23) [46].

$J=10 * J_{1}+10 * J_{2}+0.01 * J_{3}+J_{4}$

The system should be more stable by placing all the closed loop poles of the studied system in a D-shaped sector (refer Fig. 4) where $\sigma_{i}<<-\sigma_{0}$ and $\xi_{0}<<\xi_{i}$. This may be achievable only when the values of $J_{1}, J_{2}, J_{3}$ and $J_{4}$ of the fitness function are obtained while making all of the parameters of (23) mutually competitive. The components associated with the fitness function (i.e., $J_{1}, J_{2}, J_{3}$ and $J_{4}$ ) are defined in [46].

\section{4 sos algorithm}

\subsection{Overview of symbiosis}

The word 'symbiosis' has been coined from Greek vocabulary meaning 'to live together'. The word was first used by a German Scientist, de Bary to describe the association among two dissimilar living organisms which depends upon each other. The symbiotic relationship between the

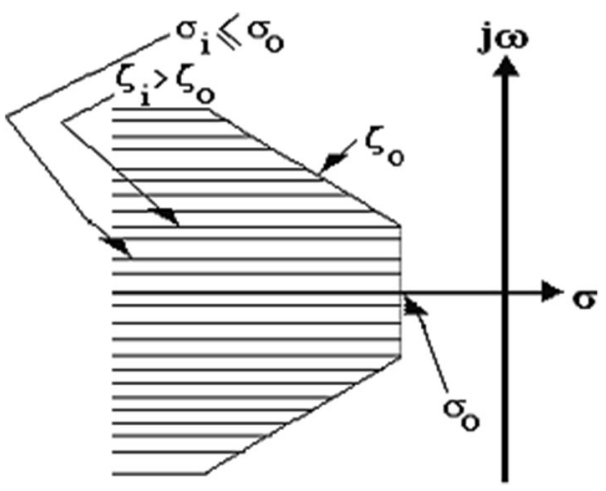

Fig. 4 D-shaped area in the negative half of s-plane [46]

organisms can be classified into following different stages: mutualism stage, commensalism stage and parasitism stage, depending on their relationships. In the first kind of relationship (i.e., in mutualism stage), organism of two unique variety of species act and two of them get profited. A perfect example of mutualism stage can be cited in case of the connection among Zebra and Oxpecker. In second type of relationship (i.e., commensalism stage), the association of symbiosis among two unique variety of living species belonging to the ecological system has been portrayed, where one species is benefitted from their interaction whilst the other is almost impervious. A perfect example of commensalism stage can be cited in case of the connection among Spider and Tree. In the last type of relationship (i.e., in parasitism), one takes its advantage by destroying the other. The relationship observed between a human body and plasmodium parasite falls in this category. Thus, during the symbiosis process, organisms with their live acclimatize and enhance their value of fitness so that they can stay lively in the ecological system over significant time-frame. By taking the above mentioned concepts, the SOS algorithm has been developed as follow [47]:

\subsubsection{Mutualism stage}

In mutualism stage of interaction, consider $X_{i}$ and $X_{j}\left(X_{i}\right.$ $\left.\neq X_{j}\right)$ are such kinds of living organisms connected with their mutualistic relationship and mutually increase their survival advantages. In this process, the new candidate solutions of considered organisms are generated using (24) and (25), respectively,

$$
\begin{aligned}
& X_{\text {inew }}=X_{i}+\operatorname{rand}(0,1) *\left(X_{\text {best }}-\text { Mutual_vector } * b f_{1}\right) \\
& X_{\text {jnew }}=X_{j}+\operatorname{rand}(0,1) *\left(X_{\text {best }}-\text { Mutual_vector } * b f_{2}\right)
\end{aligned}
$$


where,Mutual_vector $=\frac{x_{i}+x_{j}}{2}$. Here, the random number rand $(0,1)$ varies in between 0 and $1 . \ln (24)$ and $(25)$, the terms $b f_{1}$ and $b f_{2}$ are benefit factors whose values be of 1 or 2 [47]. The benefit factors actually entitle the benefit level of every organism which gets the benefit partially or fully from these mutual interactions. Mutual vector gives the association among organism $X_{i}$ and organism $X_{j}$. Equations (24) and (25) symbolize the mutual effort that is given by every organism to enhance their adaptation level to the ecological system whilst $X_{\text {best }}$ notifies the maximum possible adaptation degree. The new candidate solutions can be accepted only when fitness function of the new solutions are superior to the candidate solution of the previous one.

\subsubsection{Commensalism stage}

In commensalism stage, an $X_{j}$ organism is chosen in a random manner from the ecological system and it interacts with another $X_{i}$ organism (where $X_{i} \neq X_{j}$ ). In this process, $X_{i}$ organism gives an effort to get the benefit from the interaction and makes its best fitness. On the other hand, $X_{j}$ is completely unaffected from their interaction. Therefore, from the above interaction process, the new candidate solution i.e., $X_{\text {inew }}$ is defined in (26).

$X_{\text {inew }}=X_{i}+\operatorname{rand}(-1,1) *\left(X_{\text {best }}-X_{j}\right)$

Here, the term $\left(X_{\text {best }}-X_{j}\right)$ represents benefit factor for this phase which helps to increase the value fitness of the organism $X_{i}$.

\subsubsection{Parasitism stage}

In this section of SOS algorithm, an organism $X_{i}$ is chosen from the ecological system, similar to anapholes mosquitoes. This $X_{i}$ organism creates its parasite vector which creates another parasite which is also analogous to $X_{i}$. Thereafter, it randomly modifies its sizes and dimensions. This parasite vector randomly selects an organism $X_{j}$ from the ecosystem, known as host-to-parasite. Now, if fitness value of the $X_{i}$ parasite vector is greater than that of the host organism $X_{j}^{\prime}$ 's fitness value, at that time parasite vector $X_{i}$ keeps its place in the ecological system destroying the hosting organism $X_{j}$. If any reverse effect happens, then the organism $X_{j}$ builds its immunity and destroys the parasite vector $X_{i}$. The above described process of SOS algorithm has been outlined in Fig. 5.

\section{Results and discussions}

The results of the studied WDHPS model are obtained using MATLAB 2010a SIMULINK by changing the model input operating conditions i.e., load voltage $(U$, in p.u.) and equivalent reactance $\left(X_{e q}\right.$, in p.u.). Under a small incremental input perturbation of 0.01 p.u. in the reference voltage $\left(U_{\text {ref }}\right)$ or in the mechanical torque $\left(T_{m}\right)$ or in both, response of transient voltage $U_{t}$ is obtained. The various simulation results related to the present work are illustrated below considering number of iterations $\left(N_{0}=500\right)$, population size $\left(n_{p}=60\right)$ and run time ( $\left.t=10 \mathrm{~s}\right)$ as common parameters for all the applied algorithms (i.e., BGA, SOA and SOS). Other chosen parameters for the applied algorithms are mentioned in Appendix Section (refer Section A2).

\subsection{Eigenvalue based performance analysis}

Table 2 shows that all the tuneable parameters $\left(K_{s} T_{s} T_{s t} T_{s 2} T_{s 2}\right.$ , $K_{p}$ and $T_{d}$ for Case 1 and $K_{s} T_{s}, T_{s 1}, T_{s 2}, K_{p}, T_{d}, K_{s 1}, K_{s 2}, T_{d 1}, T_{d 2}, T_{d 3}$ and $T_{d 4}$ for Case 2 ) as well as fitness function $(J)$ values of the studied WDHPS model under different input normal operating conditions. The main motive is to minimize the value of $J$ (defined in (23)) for better compensation of reactive power of the studied WDHPS model. In Table 2, it is shown that the value of $J$ is minimal for test Case 2 and it is also observed that, among the three applied algorithms (viz. BGA, SOA and SOS), the proposed SOS algorithm gives less fitness function value. This is only possible when all the tuneable parameters of the studied model are tuned optimally. It ensures that SOS algorithm yields better results for compensation of reactive power for the proposed WDHPS model than the other employed algorithms. Eigenvalue analysis also helps to infer that the transient voltage performance may be improved by the SOS.

\subsection{Convergence profile based analysis}

The comparative BGA, SOA and SOS based convergence profile of $J$ of the studied WDHPS model has been depicted in Fig. 6a, b for different test cases under study while taking same input operating conditions (i.e., $U=0.97$ p.u. and $X_{\text {eq }}=1.08$ p.u.). It has been observed from Fig. 6 that the convergence profile for the SOS-based approach is faster than the other algorithms and the fitness value $(J)$ converges very quickly with less number of iterations. So, it may be inferred that, for stability purposes, the SOS-based approach optimizes the parameters more effectively than any other considered well known algorithms (i.e., BGA and SOA). Figure 7 represents that test Case 2 (i.e., the model consists of the controllers like Posicast, SVC and PSS3B) 
Fig. 5 The flowchart of the SOS algorithm [28]

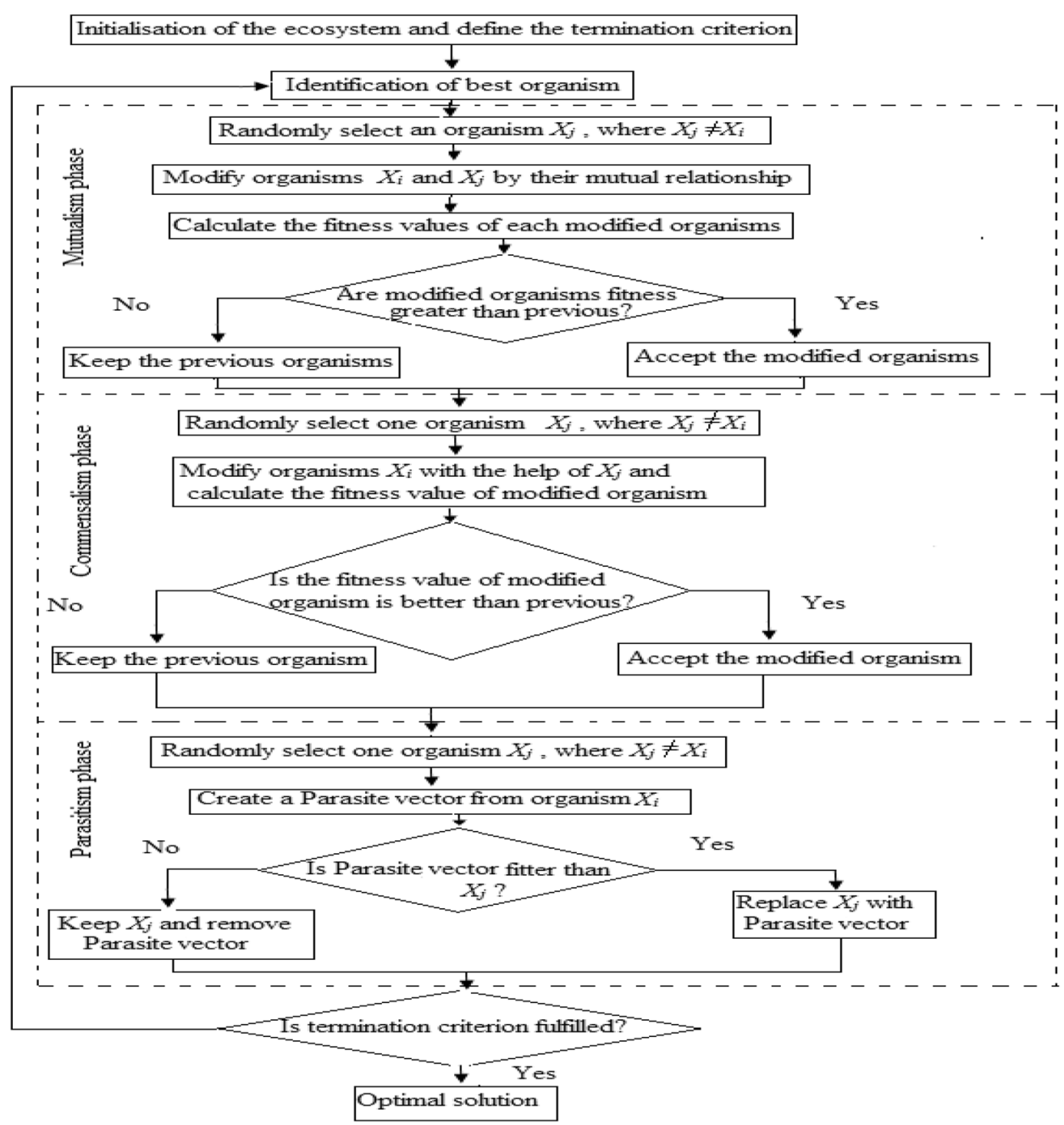

gives better results than the other considered test case which alternately means that the exciter oscillations are well diminished by the use of Posicast-PSS3B controller than the only Posicast controller.

\subsection{Time domain analysis of transient voltage response}

\subsubsection{Under constant slip model}

Generally, reactive power compensation of an isolated HPS is done by the IG and the SG under any load variation. The use of SVC based controller compensates the reactive power increasing the stability margin of the system and the action is further improved by using Posicast based SVC controller. The proposed Posicast based SVC controller makes the system more robust by enhancing the damping of the system. The transient voltage response for a particular operating condition (i.e., $U=0.97$ p.u. and $X_{e q}=1.08$ p.u.) has been plotted in Fig. 8. Transient voltage responses for the two test cases show that, for test Case
2 , the system moves faster to its stable state under any type of load disturbances. It may be apprehended from the result that the reactive power compensation capability of the studied model along with PSS3B and Posicast based SVC controller is higher than the others.

Figure $9 \mathrm{a}, \mathrm{b}$ also show that the transient voltage variation for the different applied algorithms and these two figures also present that the transient voltage response curves for the SOS-based algorithm offers quicker response than other applied algorithms under any type of small disturbances.

\subsubsection{Under variable slip/speed model}

Here, the results are obtained while considering the wind speed variation of the studied WDHPS model. The transient voltage responses of the studied model for the two test cases are obtained with constant loading condition and under variable loading. It may be noted 
Table 2 Various tuneable parameters and their optimal values of the studied WDHPS model under different test conditions and different algorithm

\begin{tabular}{|c|c|c|c|c|}
\hline Input operating conditions & Test cases & Algorithms & Optimal model parameters & Optimal value \\
\hline \multirow[t]{6}{*}{$U=0.97$ p.u.,$X_{e q}=1.08$ p.u } & \multirow[t]{3}{*}{ Case 1} & BGA & $10.00,0.0206,0.1764,0.0050,1.0000,10.7031$ & 466.6591 \\
\hline & & SOA & $10.00,0.0010,0.0500,0.0010,0.7449,3.0521$ & 466.6531 \\
\hline & & SOS & $10.00,0.0010,0.0050,0.0010,0.7405,5.3726$ & 466.6418 \\
\hline & \multirow[t]{3}{*}{ Case 2} & BGA & $\begin{array}{l}-10.000,100.00,1.2100,1.0500,1.0600,1.10,82.7734,1.1662,1.3454 \\
\quad 1.1895,1.00,6.1822\end{array}$ & 405.5334 \\
\hline & & SOA & $\begin{array}{l}-3.6643,53.9156,0.0025,0.0039,0.0023,0.0039,99.9269,0.0465 \\
0.0400,0.0419,1.1656,5.2012\end{array}$ & 377.4900 \\
\hline & & SOS & $\begin{array}{l}7.4713,90.0402,0.0047,0.0037,0.0035,0.0020,100.00,0.0500 \\
0.0431,0.0500,0.7586,4.1583\end{array}$ & 377.3532 \\
\hline \multirow[t]{6}{*}{$U=1.0$ p.u., $X_{\text {eq }}=1.08$ p.u } & \multirow[t]{3}{*}{ Case 1} & BGA & $10.00,1.0025,0.2466,0.0128,1.00,55.00$ & 466.7311 \\
\hline & & SOA & $10.00,0.0010,0.0500,0.0010,0.5000,5.7926$ & 466.6591 \\
\hline & & SOS & $10.00,0.0010,0.0050,0.0010,0.6076,4.2198$ & 466.6531 \\
\hline & \multirow[t]{3}{*}{ Case 2} & BGA & $\begin{array}{l}-10.00,100.00,1.2100,1.0500,1.0600,1.10,88.3984,1.2051,1.3688 \\
\quad 1.3142,1.00,2.0583\end{array}$ & 406.2854 \\
\hline & & SOA & $\begin{array}{l}-0.0948,95.9269,0.0045,0.0033,0.0010,0.0039,100.00,0.0397 \\
0.0340,0.0500,1.1034,1.4726\end{array}$ & 377.3728 \\
\hline & & sos & $\begin{array}{l}7.2203,55.3105,0.0047,0.0032,0.0025,0.0022,100.00,0.0500 \\
0.0431,0.0500,0.9713,3.1680\end{array}$ & 377.3532 \\
\hline \multirow[t]{6}{*}{$U=1.01$ p.u., $X_{e q}=1.08$ p.u } & \multirow[t]{3}{*}{ Case 1} & BGA & $10.00,0.0050,0.2466,0.0128,1.00,10.00$ & 466.6591 \\
\hline & & SOA & $10.00,0.0010,0.0500,0.0010,0.6458,3.9902$ & 466.6531 \\
\hline & & sos & $10.00,0.0010,0.0050,0.0010,0.5000,7.6035$ & 466.6408 \\
\hline & \multirow[t]{3}{*}{ Case 2} & BGA & $\begin{array}{l}10.00,100.000,1.2100,1.0500,1.0600,1.1000,82.4219,0.5038 \\
0.4960,0.9947,1.00,4.5632\end{array}$ & 408.7398 \\
\hline & & SOA & $\begin{array}{l}-2.7082,59.6005,0.0038,0.0026,0.0017,0.0018,100.000,0.0500 \\
\quad 0.0430,0.0275,1.1943,4.5434\end{array}$ & 377.4905 \\
\hline & & sos & $\begin{array}{l}-4.0573,91.1718,0.0033,0.0040,0.0029,0.0041,100.00,0.0500 \\
0.0431,0.0500,0.8567,4.7572\end{array}$ & 377.3532 \\
\hline \multirow[t]{6}{*}{$U=0.97$ p.u.,$X_{e q}=0.93$ p.u } & \multirow[t]{3}{*}{ Case 1} & BGA & $10.00,0.2622,0.2544,0.0050,1.00,21.6016$ & 466.6631 \\
\hline & & SOA & $10.00,0.0010,0.0500,0.0010,0.7481,10.00$ & 466.6591 \\
\hline & & SOS & $10.00,0.0010,0.0050,0.0010,0.8856,5.9291$ & 466.6531 \\
\hline & \multirow[t]{3}{*}{ Case 2} & BGA & $\begin{array}{l}-10.00,100.00,1.2100,1.0500,1.0600,1.1000,99.6484,0.2544 \\
0.2466,0.9947,1.0000,8.4506\end{array}$ & 383.4715 \\
\hline & & SOA & $\begin{array}{l}-3.2324,98.4720,0.0032,0.0041,0.0037,0.0035,100.00,0.0417 \\
0.0358,0.0500,1.1257,3.1488\end{array}$ & 377.5576 \\
\hline & & sos & $\begin{array}{l}5.4492,29.1689,0.0037,0.0019,0.0040,0.0049,100.00,0.0500 \\
\quad 0.0431,0.0500,0.5382,9.1903\end{array}$ & 377.3532 \\
\hline \multirow[t]{6}{*}{$U=1.0$ p.u., $X_{e q}=0.93$ p.u } & \multirow[t]{3}{*}{ Case 1} & BGA & $10.00,0.0050,0.2466,0.0128,1.0000,10.00$ & 466.6591 \\
\hline & & SOA & $10.00,0.0010,0.0500,0.0010,0.5373,6.3117$ & 466.6531 \\
\hline & & sos & $10.00,0.0010,0.0050,0.0010,0.6209,2.8422$ & 466.6475 \\
\hline & \multirow[t]{3}{*}{ Case 2} & BGA & $\begin{array}{l}-10.00,100.00,1.2100,1.0500,1.0600,1.100,83.8281,1.0103,1.1194 \\
1.2129,1.000,7.7236\end{array}$ & 388.1078 \\
\hline & & SOA & $\begin{array}{l}3.3900,54.7439,0.0023,0.0012,0.0050,0.0025,98.2605,0.0176 \\
\quad 0.0149,0.0433,1.3024,2.4444\end{array}$ & 378.3249 \\
\hline & & SOS & $\begin{array}{l}-3.2871,77.8043,0.0030,0.0024,0.0044,0.0021,100.00,0.0500 \\
0.0431,0.0500,0.7912,8.6200\end{array}$ & 377.3532 \\
\hline
\end{tabular}


Table 2 (continued)

\begin{tabular}{|c|c|c|c|c|}
\hline Input operating conditions & Test cases & Algorithms & Optimal model parameters & Optimal value \\
\hline \multirow[t]{6}{*}{$U=1.01$ p.u.,$X_{\text {eq }}=0.93$ p.u } & \multirow[t]{3}{*}{ Case 1} & BGA & $10.00,0.5038,0.3089,0.0050,1.0000,32.50$ & 466.6865 \\
\hline & & SOA & $10.00,0.0010,0.0500,0.0010,0.7007,8.7817$ & 466.6591 \\
\hline & & sos & $10.00,0.0010,0.0050,0.0010,0.8240,8.3057$ & 466.6531 \\
\hline & \multirow[t]{3}{*}{ Case 2} & BGA & $\begin{array}{l}-10.00,100.00,1.2100,1.0500,1.0600,1.100,99.6484,0.0907,0.0829 \\
\quad 0.5271,1.000,3.2468\end{array}$ & 379.1248 \\
\hline & & SOA & $\begin{array}{l}1.8518,78.6453,0.0012,0.0027,0.0030,0.0025,100.000,0.0244, \\
0.0207,0.0372,1.2611,4.5906\end{array}$ & 378.1340 \\
\hline & & sos & $\begin{array}{l}-4.6092,26.2490,0.0018,0.0021,0.0046,0.0046,100.00,0.0500, \\
0.0431,0.0500,0.6823,4.7429\end{array}$ & 377.3532 \\
\hline
\end{tabular}

Model parameters: Case 1: Model + SVC + Posicast, Case 2: Model + SVC+ Posicast + PSS Results of interest are only bold faced
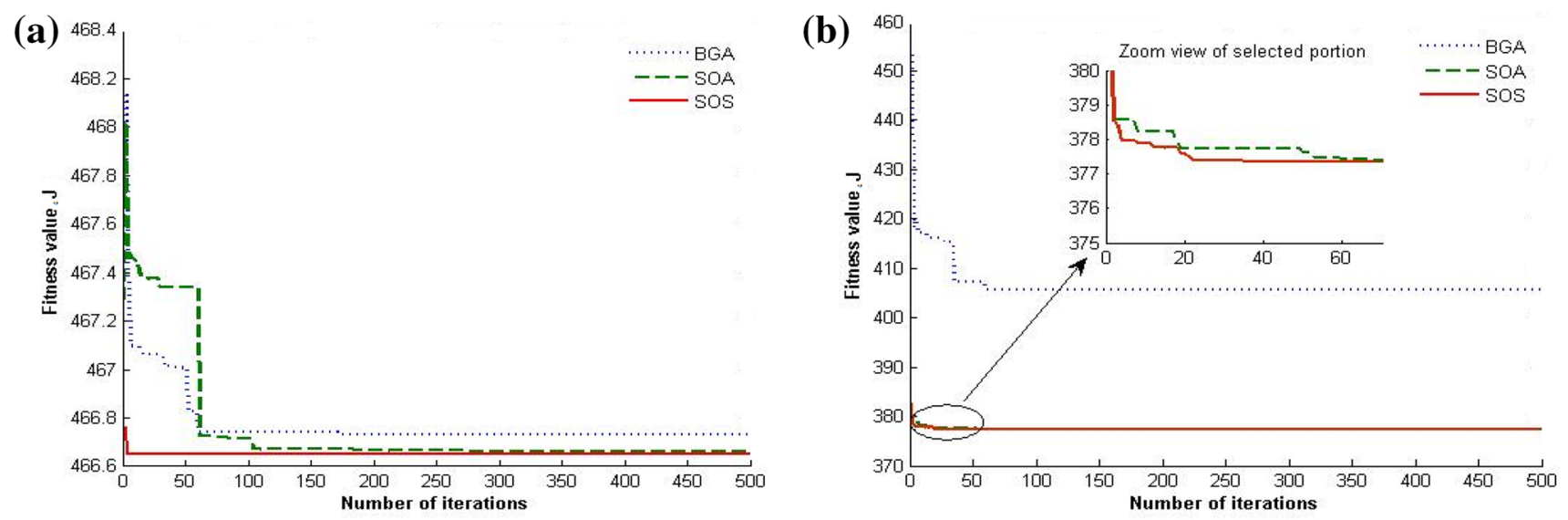

Fig. 6 Convergence profiles of various algorithms pertaining to $U=0.97$ p.u. and $X_{\text {eq }}=1.08$ p.u. for: a Model+SVC+Posicast and $\mathbf{b}$ Model + SVC + Posicast + PSS

Fig. 7 Comparative convergence profile of fitness values of the studied WDHPS model for $U=1.01$ p.u., $X_{e q}=1.08$ p.u

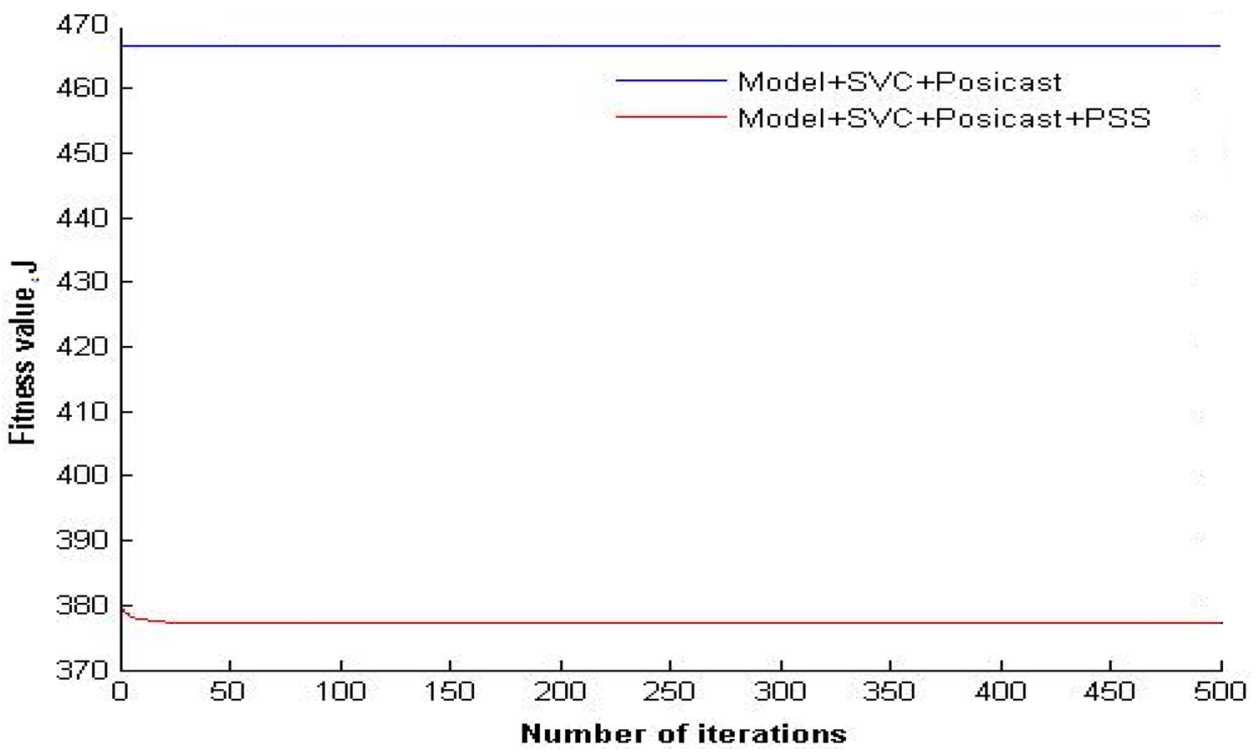


Fig. 8 Comparative transient response profile for studied WDHPS model under $U=0.97$ p.u. and $X_{e q}=1.08$ p.u



(a)

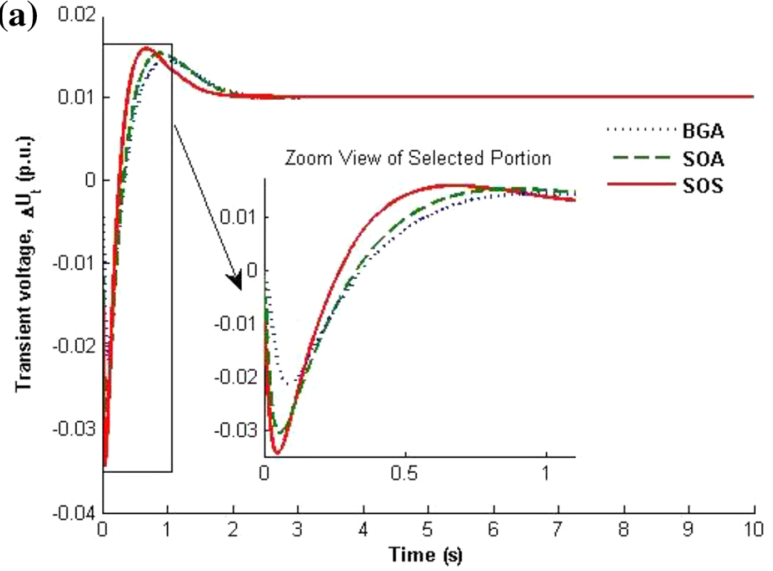

(b)

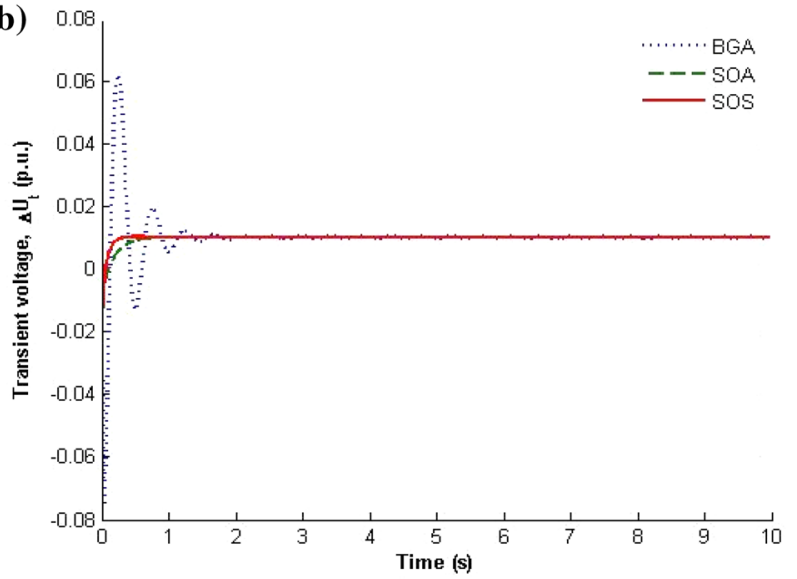

Fig. 9 Comparative transient response of different algorithms for $U=1.01$ p.u. and Xeq=0.93 p.u. a Model+SVC+Posicast and b Model + SVC + Posicast + PSS

from the results that the transient voltage response (see Fig. 10) is better for Case 2.

The values of the various parameters are also given in Table 3 and it may be easily inferred from the results that, by using SOS algorithm, the performance parameters become optimal and the other associated power system response characteristics are better for SVC with Posicast-PSS controlled model than the SVC with Posicast controlled one. Figure 11 depicts the transient characteristic of the studied WDHPS model under load variation conditions and it would be fascinating to note from this figure that better result is obtained for Case 2 .

\subsection{FOD-based analysis}

To acquire better damping of electromechanical oscillations, FOD based analysis is also carried out for the incremental change in terminal voltage. Lesser values of FOD imply better relative stability of the system and it is achieved by the way of enhancing damping of the system. FOD is calculated in terms of $E_{s s}, t_{r}, t_{s}$ and $M_{p}$, as defined in (22).

The FOD value has been included in the same table. It is shown in Table 4 that the FOD is lesser in case of SOS based approach than the other comparative algorithms. 
Fig. 10 Comparative transient profile of the studied model under variable wind speed for $U=1.01$ p.u. and $X e q=1.08$ p.u

Table 3 Transient response characteristic of different test models with $U=1.01$ p.u. and $X_{\text {eq }}=1.08$ p.u

Fig. 11 Comparative voltage response under varying load condition for $U=0.97$ p.u. and $X e q=0.93$ p.u



\begin{tabular}{lrrllll}
\hline Test conditions & \multicolumn{1}{c}{$t_{r}(\mathrm{~s})$} & \multicolumn{1}{c}{$t_{s}(\mathrm{~s})$} & $M_{p}(\%)$ & \multicolumn{1}{l}{$E_{s s}$} & FOD & Convergence value J \\
\hline Case 1 & 7.1935 & 7.5786 & 0.0139 & 0.010 & 34.1567 & 465.1888 \\
Case 2 & 10.8019 & 10.8762 & $1.0196^{*} 10^{-05}$ & $-4.547^{*} 10^{-07}$ & 32.8142 & 377.3087 \\
\hline
\end{tabular}

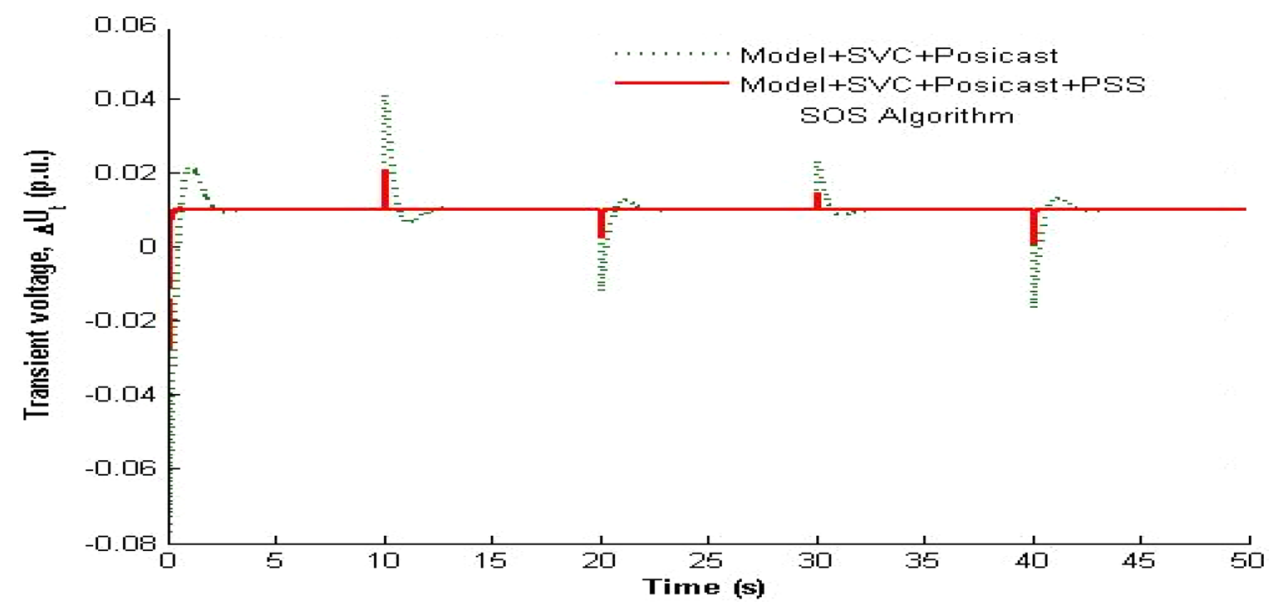

Table 4 FOD values and transient characteristics parameters of test Case 2 for $U=1.0$ p.u. and $X_{e q}=0.752$ p.u

\begin{tabular}{lrrlll}
\hline Algorithms & \multicolumn{1}{c}{$t_{r}(\mathrm{~s})$} & \multicolumn{1}{c}{$t_{s}(\mathrm{~s})$} & $M_{p}(\%)$ & \multicolumn{1}{l}{$E_{s s}$} & FOD \\
\hline BGA & 6.6569 & 6.7241 & 0.0102 & 0.0100 & 34.3518 \\
SOA & 7.1499 & 7.2225 & 0.0102 & 0.0100 & 34.1704 \\
SOS & 38.8464 & 38.9218 & 0.0101 & 0.0100 & 22.5099 \\
\hline
\end{tabular}

Table 4 includes $E_{s s}, t_{r}, t_{s}$ and $M_{p}$ values of the studied WDHPS model for test Case 2 for different comparative algorithms having the operating condition of $U=1.0$ p.u. and $X_{e q}=0.752$ p.u.

\subsection{Performance analysis in terms of performance indices}

The various performance indices (i.e., IAE, ISTE and ISE) values are calculated for all the input operating conditions 
pertaining to different comparative algorithms as well as for different test cases at the end of the developed programs. The values of various performance indices for an input condition of $U=1.0$ p.u. and $X_{e q}=0.752$ p.u. are presented in Table 5 on sample basis. From the performance indices values presented in the table, the same conclusion may be drawn in connection with the reactive power compensation methodology of the studied WDHPS model for test Case 2 as well as the optimizing performance of the adopted optimizing algorithms.

\subsection{Comparative study among the different controllers}

In this section, the study has been carried out with various used controllers in the WDHPS other than only SVC-Posicast and SVC-Posicast with PSS. Here, the study mainly focused on the WDHPS with SVC-PSS controller and only PSS controller. The controller parameters are being optimized by the SOS technique due to its superior nature of parameter optimization for the reactive power optimization in the WDHPS model. The obtained results are compared with the used previous controller structure. The comparative transient voltage profile is given in Fig. 12. Table 6 consists of different parameter values after the optimization and the different transient response parameters for $U=1.01$ p.u. and $X e q=1.05$ p.u on sample basis. From the Fig. 12 and Table 6, it may be concluded that the reactive power optimization and the stability improvement of the WDHPS would be better for the SVC-Posicast with PSS controller.

Table 5 Values of various performance indices for different test cases vis-â-vis different algorithms

\begin{tabular}{|c|c|c|c|c|c|}
\hline Input operating condition & Test cases & $\begin{array}{l}\text { Applied algo- } \\
\text { rithms }\end{array}$ & $\operatorname{IAE}\left(\times 10^{3}\right)$ & ISTE & ISE \\
\hline \multirow{6}{*}{$\begin{array}{l}U=1.0 \text { p.u., } \\
X_{e q}=0.752 \text { p.u }\end{array}$} & \multirow{3}{*}{$\begin{array}{l}\text { MODEL +SVC + } \\
\text { Posicast }\end{array}$} & BGA & 2.6089 & 1578.9 & 55.0863 \\
\hline & & SOA & 2.1913 & 1267.3 & 35.4723 \\
\hline & & SOS & 1.8196 & 1020.5 & 31.0826 \\
\hline & \multirow{3}{*}{$\begin{array}{l}\text { MODEL + SVC + } \\
\text { Posicast + } \\
\text { PSS }\end{array}$} & BGA & 2.0583 & 939.1802 & 33.9601 \\
\hline & & SOA & 1.7803 & 904.0770 & 17.7285 \\
\hline & & sos & 1.7154 & 900.9818 & 16.8496 \\
\hline
\end{tabular}

Fig. 12 Transient voltage profiles of WDHPS model for the differently used controllers




Table 6 Optimal controller parameters and transient response specifications for differently test controllers

\begin{tabular}{|c|c|c|}
\hline Test controller & Optimal parameters & $\begin{array}{l}\text { Transient Response } \\
\text { Parameters }\left(M_{\mathrm{p}} \text { and }\right. \\
\left.E_{\mathrm{ss}}\right)\end{array}$ \\
\hline Model + PSS & -7.269633 .05570 .01410 .00150 .01650 .2024 & 0.02100 .0158 \\
\hline Model + SVC-PSS & 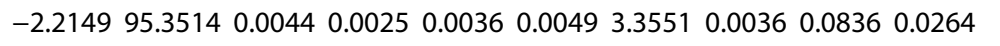 & 0.02300 .0100 \\
\hline Model + SVC-Posicast & 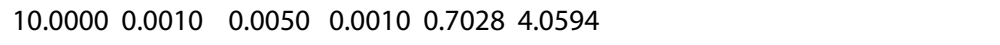 & 0.01460 .0100 \\
\hline Model + SVC-Posicast + PSS & 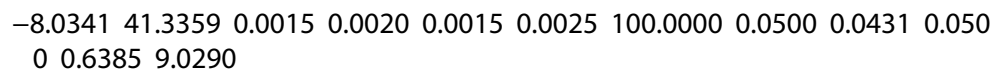 & 0.01020 .0100 \\
\hline
\end{tabular}

\subsection{Robustness study of the controller}

The robustness of the considered controller (i.e., SVC with Posicast controller and SVC and Posicast with PSS controller) has been examined with the $\pm 10 \%$ load disturbances in the step load. For the step load disturbances, the transient voltage profiles of the WDHPS model of different controller structure has been given in Fig. 13. It is observed that, for the given load disturbances, the transient oscillations of the terminal voltage is more for the applied SVC with Posicast controller whereas the oscillations is less when SVC and Posicast with PSS controller has been considered. Another major observation from Fig. 13 is that the range of variations in oscillations is wide for SVC with Posicast controller than SVC and Posicast with PSS controller. Therefore, the studied SVC with Posicast and PSS controller is more robust for the wide range of load disturbances.

\section{Conclusions}

In the studied hybrid model, deficit of reactive power is truly compensated by proper adjusting of the different controller parameters of the hybrid model with the help of soft computing based algorithm. Further, the Posicast controller is used to improve the stability of the model and better system performance under various disturbances. Robustness of the Posicast controller also studied successfully. Again, the PSS3B model is incorporated to achieve less oscillation during any disturbances. So, in this studied hybrid model, the Posicast controller along with PSS3B controller damp out even small oscillations and negative damping of the system properly. Throughout the study it has also been observed that the SOS algorithm is better for its parameter optimization and better reactive power compensation as compared to other applied algorithms (i.e., BGA and SOA) adopted in this study.


Fig. 13 Transient Voltage response of the WDHPS with different load disturbances a Model+SVC+Posicast and b Model +SVC + Posicast + PSS 


\section{Declarations}

Conflicts of interest On behalf of all authors, the corresponding author states that there is no conflict of interest.

Open Access This article is licensed under a Creative Commons Attribution 4.0 International License, which permits use, sharing, adaptation, distribution and reproduction in any medium or format, as long as you give appropriate credit to the original author(s) and the source, provide a link to the Creative Commons licence, and indicate if changes were made. The images or other third party material in this article are included in the article's Creative Commons licence, unless indicated otherwise in a credit line to the material. If material is not included in the article's Creative Commons licence and your intended use is not permitted by statutory regulation or exceeds the permitted use, you will need to obtain permission directly from the copyright holder. To view a copy of this licence, visit http://creativecommons .org/licenses/by/4.0/.

\section{Appendix 1: Model parameters}

The various constants associated with the SG, the IG and the excitation system blocks of Fig. 2 are presented below.

$$
\begin{array}{r}
K_{1}=\frac{U \cos \delta}{X_{d}^{\prime}}, K_{2}=\frac{\left(E^{\prime} \cos \delta-2 U\right)}{X_{d}^{\prime}}, K_{3}=\frac{X_{d}^{\prime}}{X_{d}}, K_{4}=\frac{\left(X_{d}-X_{d}^{\prime}\right) \cos \delta}{X_{d}^{\prime}} \\
{ }^{\prime} K_{5}=\frac{2 U X_{e q}^{\prime}}{\left(R_{y}^{2}+X_{e q}^{2}\right)}, \quad K_{6}=\frac{X_{e q}}{R_{p}-\frac{\left(R_{y}^{2}+x_{e q}^{2}\right)}{2 R_{y}}}, R_{y}=R_{p}+R_{e q}, R_{p}=\frac{r_{2}}{s}(1-s) \\
{ }_{,} X_{e q}=x_{1}+x_{2^{\prime}}^{\prime}, R_{e q}=r_{1}+r_{2^{\prime}}^{\prime} K_{7}=\frac{2 U}{R_{y}^{2}+X_{e q}^{2}}\left[X_{e q}-\frac{R_{p} X_{e q}}{\left(R_{p}-\frac{\left(R_{y}^{2}+x_{e q}^{2}\right)}{2 R_{y}}\right)}\right] .
\end{array}
$$

Various values of the WDHPS Model (for $150 \mathrm{~kW}$ of each generating sources and $250 \mathrm{~kW}$ of load) are as follows:

(a) For SG based diesel system, $U=1.0$ p.u., $E_{q}=1.12418$ p.u., $E_{q}^{\prime}=0.9804$ p.u., $\delta=17.2483^{\circ}, X_{d}=1.0$ p.u., $X_{d}^{\prime}=0.15$ p.u. $T_{d 0}^{\prime}=5.0 \mathrm{~s}, P_{S G}=0.4$ p.u. $\mathrm{kW}$ and $Q_{S G}=0.2$ p.u. kW.

(b) For IG based wind system, $r_{1}=r_{2}^{\prime}=0.19$ p.u., $x_{1}=x_{2}^{\prime}=0.56$ p.u., $s=-3.5 \%, \eta=90 \%$, Power factor $=0.9, P_{I G}=0.6$ p.u. kW, $Q_{I G}=0.291$ p.u. kVAr and $P_{\text {in }}=0.667$ p.u. kW.

(c) For the applied load model, $P_{L}=1.0$ p.u. kW, $Q_{L}=0.75$ p.u. kVAr, Power factor $=0.8$

(d) For the considered SVC controller, $Q_{\text {sVC }}=0.841$ p.u. $\operatorname{kVAr}, \alpha=138.8^{0}$.

(e) The other values related to the studied model are taken as $K_{u}=6.667, T_{u}=7.855^{*} 10^{-4} \mathrm{~s}, \mathrm{H}=1.0, \mathrm{D}=0.8$, $\omega_{0}=314, K_{a}=200, T_{a}=0.01 \mathrm{~s}, T_{r}=0.02 \mathrm{~s}, K_{a 4}=1.478$, $K_{a 5}=3.8347$.

\section{Appendix 2 Algorithm parameters}

The different parameters considered for the adopted algorithms are as follow:

(a) For BGA [26]: The current work considered as number of bits $=$ (number of parameters $)^{*} 8$, crossover rate $=80 \%$ and mutation probability $=0.001$.

(b) For SOA $[26,48]$ : The main SOA parameters involved in the simulation are population size $\left(n_{p}\right)$ and the number of considered subpopulations $=\left(n_{p} / 3\right)$. The membership function parameters of the Fuzzy reasoning are $\mu_{\max }=0.95, \mu_{\min }=0.0111, \omega_{\max }=0.8$ and $\omega_{\min }=0.2$.

(c) For SOS [47]: There is no such algorithm defined parameters.

\section{References}

1. Hunter R, Elliot G (eds) (1994) Wind-Diesel Systems: A Guide to the Technology and its Implementation. Cambridge University Press, Cambridge

2. Hingorani NG, Gyugyi L, El-Hawary M (2000) Understanding FACTS: Concepts and Technology of Flexible AC Transmission Systems. IEEE Press, New York

3. Bansal RC (2005) Automatic reactive power control of isolated wind-diesel hybrid power systems. IEEE Trans of Ind Electronics 53(4):1116-1126

4. Bansal RC, Bhatti TS, Kothari DP (2004) Automatic reactive power control of isolated wind-diesel hybrid power systems for variable wind speed/slip. Int J Electr Power Compon Syst 32(9):901-912

5. Bansal RC, Bhatti TS, Kothari DP, Bhat S (2005) Reactive power control of isolated wind-diesel-micro-hydro hybrid power systems using matlab/simulink. Int J Glob Energy Issues 24(1-2):86-99

6. Das DC, Sriramoju H, Ranjan S, Sinha N (2017) Voltage control of fuel cell-wind-diesel hybrid power system using FA based SVC and AVR controller. 2017 IEEE Region 10 Humanitarian Technology Conference, Dhaka 606-609.

7. Mohanty A, Patra S, Ray PK (2016) Robust fuzzy-sliding mode based UPFC controller for transient stability analysis in autonomous wind-diesel-PV hybrid system. IET Gener Transm Distrib 10(5):1248-1257

8. Mahato T, Mukherjee V (2015) A novel quasi-oppositional harmony search algorithm and fuzzy logic controller for frequency stabilization of an isolated hybrid power system. Int J Electr Power Energy Syst 66:247-261

9. Banerjee A, Mukherjee V, Ghoshal SP (2014) An oppositionbased harmony search algorithm for engineering optimization problems. Ain Shams Eng J 5(1):85-101

10. Mathur RM, Varma RK (2002) Thyristor based FACTs Controllers for Electrical Transmission Systems. Wiley, New Jersy

11. Lee SY, Wu CJ, Chang WN (2001) A compact control algorithm for reactive power compensation and load balancing with static VAR compensator. Electr Power Syst Res 58(2):63-70

12. Uzunoglu M, Onar OC (2008) Static VAR compensator based reactive power management for SOFC power plants. Int J Hydro Energy 33(9):2367-2378 
13. Sharma P, Bhatti TS, Ramakrishna KSS (2010) Control of reactive power of autonomous wind-diesel hybrid power systems. In power electronics, drives and energy systems (PEDES) \& 2010 power India 1-6.

14. Mohanty A, Viswavandya M (2015) A novel ANN based UPFC for voltage stability and reactive power management in a remote hybrid system. Procedia Comput Sci 48:555-560

15. Srithorn P, Theejanthuek N (2014) The enhanced performance svc for transient instability oscillation damping. Energy Procedia $56: 510-517$

16. Hammad AE (1986) Analysis of power system stability enhancement by static VAR compensators. IEEE Trans Power Syst 1(4):222-227

17. Hammad AE, El-Sadek M (1984) Application of thyristor controlled VAR compensator for damping sub-synchronous oscillations in power systems. IEEE Trans Power Appar Syst 1:198-212

18. Yuan-Yih H, Chi-Jui W (1988) Adaptive control of a synchronous machine using the auto-searching method. IEEE Trans Power Syst 3(4):1434-1440

19. Taylor CW, Scott G, Hammad A (1994) Static VAR compensator models for power flow and dynamic performance simulation. IEEE Trans Power Syst Inst Electr Electron Eng 9(1):229-240

20. Cheng $\mathrm{CH}$, Hsu YY (1992) Damping of generator oscillations using an adaptive static VAR compensator. IEEE Trans Power Syst 7(2):718-725

21. Padiyar KR, Varma RK (1991) Damping torque analysis of static VAR system controllers. IEEE Trans Power Syst 6(2):458-465

22. Mathur RM (1986) Stabilisation Techniques in Power Systems Static VAR Compensation. In Proc, IFAC Symp

23. De Oliveira RA, de Medeiros Júnior MF, Menezes RFA (2014) Application of genetic algorithm for optimization on projects of public illumination. Electric Power Syst Res 117:84-93

24. Saxena NK, Kumar A (2016) Reactive power control in decentralized hybrid power system with STATCOM using GA, ANN and ANFIS methods. Int J Electr Power Energy Syst 83:175-187

25. Sundaram V, Jayabarathi T (2011) Load frequency control using PID tuned ANN controller in power system. In: 2011 1st International conference on electrical energy systems, Chennai, India, 2011, pp 269-274. https://doi.org/10.1109/ICEES.2011.5725341

26. Banerjee A, Mukherjee V, Ghoshal SP (2013) Modeling and seeker optimization based simulation for intelligent reactive power control of an isolated hybrid power system. Swarm Evolut Comput 13:85-100

27. Banerjee A, Mukherjee V, Ghoshal SP (2014) Intelligent fuzzybased reactive power compensation of an isolated hybrid power system. Int J Electr Power Energy Syst 57:164-177

28. Cheng MY, Prayogo D (2014) Symbiotic organisms search: A new metaheuristic optimization algorithm. Comput Struct 139:98-112

29. Ghorbani A, Pourmohammad S, Ghazizadeh MS (2008) Mitigation of oscillations due to changing the reference signal of the excitation system using a Posicast controller. In 2008 12th International Middle-East Power System Conference 57-61.

30. Aghamohammadi MR, Ghorbani A, Pourmohammad S (2008) Enhancing transient and small signal stability in power systems using a Posicast excitation controller. In 2008 43rd International Universities Power Engineering Conference 1-5.
31. Smith OJM (1957) Posicast control of damped oscillatory systems. Proceed IRE 45(9):1249-1255

32. Hung JY (2003) Feedback control with Posicast. IEEE Trans Ind Electron 50(1):94-99

33. Singh RLR, Rose RL, Chinnu J (2016) Voltage control of a statcom using posicast and $p+$ resonant controller at a fixed speed induction generator wind farm. J Electr Eng Sci 2(2):12-23

34. Ghorbani H, Candela Jl, Luna A, Rodriguez P (2014) Posicast control-A novel approach to mitigate multi-machine power system oscillations in presence of wind farm. 2014 IEEE PES General Meeting|Conference \& Exposition, National Harbor, MD, 1-5.

35. Ghorbani A, Masoudi S, Shabani A (2012) Application of the Posicast control method to static shunt compensators. Turkish J Electr Eng Comput Sci 20:1100-1108

36. Mirfendereski S, Wahab NIA, Othman JJML (2014) Mitigation of power system small signal oscillation using Posicast controller and evolutionary programming. J Eng Sci Technol 10(1):50-67

37. Ghorbani H, Monadi M, Ghorbani A, Candel JI (2018) Application of new Posicast control method to synchronous generator excitation system. J Power Technol 98(4):336-344

38. Hung JY (2002) Application of Posicast principles in feedback control. In IEEE International Symposium on Industrial Electronics 2.

39. Kalantar M (2010) Posicast control within feedback structure for a DC-DC single ended primary inductor converter in renewable energy applications. Appl Energy 87(10):3110-3114

40. Yumuk E, Güzelkaya M, Eksin I (2021) Modified posicast control design method based on the parameters of a fractional order system. ASME J Dyn Sys Meas Control 143(4):041009. https:// doi.org/10.1115/1.4049549

41. Padiyar KR (1996) Power Systems Dynamics, Stability and Control. Interline Publishing, Bangalore, India

42. Xi-Fan W, Song Y, Irving M (2008) Modern Power Systems Analysis. Springer, New York

43. Jabr RA, Pal BC, Martins N, Ferraz JCR (2010) Robust and coordinated tuning of power system stabilizer gains using sequential linear programming. IET Gener Transm Distrib 4(8):893-904

44. Gaing ZL (2004) A particle swarm optimization approach for optimum design of PID controller in AVR system. IEEE Trans Energy Convers 19:384-391

45. Kundur P (2006) Power System Stability and Control. TataMcGraw-Hill, India

46. Shaw B, Banerjee A, Ghoshal SP, Mukherjee V (2011) Comparative seeker and bio-inspired fuzzy logic controllers for power system stabilizers. Int J Electr Power Energy Syst 33(10):1728-1738

47. Verma S, Saha S, Mukherjee V (2017) A novel symbiotic organisms search algorithm for congestion management in deregulated environment. J Exp Theor Artif Intell 29(1):59-79

48. Dai C, Chen W, Zhu Y, Zhang X (2009) Seeker optimization algorithm for optimal reactive power dispatch. IEEE Trans Power Syst 24(3):1218-1231

Publisher's Note Springer Nature remains neutral with regard to jurisdictional claims in published maps and institutional affiliations. 